\title{
Developmental Changes in Neurally Mediated Ion Transport in Piglet Distal Colon
}

\author{
THOMAS A. BACH AND HANNAH V. CAREY \\ Department of Comparative Biosciences, School of Veterinary Medicine University of \\ Wisconsin, Madison, Wisconsin 53706
}

\section{ABSTRACT}

To better understand the role of enteric nerves in the regulation of colonic ion transport in neonates, we examined the effects of endogenous and exogenous neurotransmitters on ion transport across distal colonic tissues of piglets. Tissues were obtained from full-term fetuses; newborns; suckling piglets killed $1 \mathrm{~d}, 5 \mathrm{~d}$, and $14 \mathrm{~d}$ after birth; and 21-d-old piglets that had been weaned for $2 \mathrm{~d}$. Colonic tissues were stripped of external muscle layers and mounted in Ussing flux chambers. Short-circuit current (Isc), a measure of active ion transport, and transmural potential difference were lowest in fetal colons and increased during postnatal development. Tissue conductance remained constant throughout development until d 14 and then rose sharply after weaning. Blockade of enteric neural transmission with tetrodotoxin reduced basal Isc compared with control tissues in fetal, newborn, and 1-d-old piglets but had no effect in older animals. The $\mathrm{Na}^{+}$-channel blocker amiloride had no effect on basal Isc in fetal tissues but significantly reduced Isc in all other groups, with the effect increasing with age. Isc responses to electrical field stimulation of enteric neurons were similar in fetal through

The extrinsic and intrinsic nerves that innervate the gastrointestinal tract are important modulators of intestinal ion transport $(1,2)$. Neuromodulation of intestinal transport is a key way in which the gut processes sensory information from luminal and systemic stimuli and initiates appropriate effector mechanisms that maintain the proper consistency and composition of luminal contents (1). Although a number of studies have now identified neural pathways and specific neurotransmitters that regulate transport function, virtually all of these reports have focused on adult animals or humans or at least young animals that have already been weaned. Consequently, apart from the study by Carey and Cooke (3) in

Received May 4, 1993; accepted March 4, 1994.

Correspondence and reprint requests: Hannah V. Carey, Ph.D., Department of Comparative Biosciences, University of Wisconsin, 2015 Linden Drive West. Madison, WI 53706.

Supported by a grant from the University of Wisconsin School of Veterinary Medicine Food Animal Research Fund. 14-d-old piglets and then increased after weaning. Increases in Isc after serosal additions of carbachol $(10 \mu \mathrm{M})$, serotonin $(10 \mu \mathrm{M})$, or norepinephrine $(10 \mu \mathrm{M})$ in fetal and newborn piglets were as great or greater than in the older piglets. For serotonin and norepinephrine, Isc responses rose sharply immediately after weaning. In 1-d-old piglets, Isc responses to all stimuli were reduced significantly by removal of $\mathrm{Cl}^{-}$ions from the bathing solutions. At all ages Isc responses were inhibited by bumetanide $(10 \mu \mathrm{M})$ but were not affected by amiloride. These results demonstrate that colonic $\mathrm{Cl}$ secretion evoked by endogenous or exogenous addition of neurotransmitters is well developed at an early age in piglets. (Pediatr Res 36: 144-151, 1994)
Abbreviations
Isc, short-circuit current
PD, potential difference
TTX, tetrodotoxin
EFS, electrical field stimulation
5HT, serotonin

the suckling mouse jejunum, little is known of the role of nerves in regulating ion transport in gastrointestinal tissues of young mammals or whether neurally mediated ion transport changes during the postnatal period. This information is critical to a full understanding of the mechanisms associated with diarrheal and other gastrointestinal diseases in neonates.

The aim of the present study was to examine the effects of endogenous and exogenous neurotransmitters on colonic ion transport during postnatal development in piglets. Although the role of hormonal signals, particularly aldosterone, in mediating developmental changes in colonic ion transport has been studied in several species (4-10), the effect of enteric neurotransmitters on colonic ion transport at an early age is not known. In this investigation we studied in vitro preparations of distal colon from piglets ranging in age from full-term fetal stage through early weaning ( $3 \mathrm{wk}$ ). For each age group we studied 1) the effect of ongoing neural activity on main- 
tenance of basal ion transport; 2) ion transport responses to EFS of colonic submucosal nerves that evokes endogenous release of neuroactive agents; and 3) ion transport responses to exogenous addition of neurotransmitters.

\section{METHODS}

Full-term fetal pigs were obtained from crossbred gilts at d 111-113 of gestation. Older piglets were housed at the University of Wisconsin Swine Research Facility until transport to the School of Veterinary Medicine where experiments were carried out. Newborn piglets was allowed to suckle for $2-8 \mathrm{~h}$ before being killed. Older piglets remained with the sow until death on $\mathrm{d} 1,5$, or 14 after birth. An additional group of weaned piglets was killed $23 \mathrm{~d}$ after birth; these piglets had been removed from the sow at d 21 and were provided solid food only from d 21 to $\mathrm{d} 23$. The piglets and gilts were killed by electrocution, and segments of distal colon were removed and immediately placed in ice-cold KrebsRinger's solution. This method of death, which was approved by the University of Wisconsin School of Veterinary Medicine Animal Care and Use Committee, had no effect on ion transport responses of colonic tissues compared with tissues obtained from animals killed with pentobarbital. The Krebs-Ringer solution contained (in $\mathrm{mM}): \mathrm{Na}^{+}, 152 ; \mathrm{Cl}^{-}, 143 ; \mathrm{K}^{+}, 6 ; \mathrm{Ca}^{++}, 3 ; \mathrm{Mg}^{++}, 0.7$; $\mathrm{HCO}_{3}, 20 ; \mathrm{HPO}_{4}, 1.3 ; \mathrm{H}_{2} \mathrm{PO}_{4}, 0.3$. The external muscle layers were removed by blunt dissection, and adjacent segments were mounted as flat sheets in Ussing-type flux chambers. The serosal surface area exposed was $0.5 \mathrm{~cm}^{2}$ or $0.785 \mathrm{~cm}^{2}$. Solutions bathing both sides of the tissues were maintained at $39^{\circ} \mathrm{C}$ (porcine core temperature) and contained D-glucose $(11.5 \mathrm{mM})$ or mannitol $(11.5 \mathrm{mM})$ in serosal and mucosal solutions, respectively. Solutions were gassed with a $95 \% \mathrm{O}_{2}-5 \% \mathrm{CO}_{2}$ mixture and buffered at $\mathrm{pH}$ 7.2. In the $\mathrm{Cl}^{-}$-free experiments performed with tissues from 1-d-old piglets, gluconate salts were substituted for $\mathrm{Cl}^{-}$ions in the bathing solutions.

Crypt depths. A $1-\mathrm{cm}^{2}$ piece of distal colon adjacent to segments used for transport experiments was removed and fixed in buffered formalin. Sections were blocked in paraffin, sectioned at $6 \mu \mathrm{m}$, mounted on slides, and stained with hematoxylin and eosin. A minimum of five crypts per animal was used to determine mean crypt depth; the mean value from each individual was then used in the total data set.

Electrical measurements. Transmural electrical PD was measured with a pair of Ringer-agar bridges connected to calomel half-cells. A second pair of silver-silver $\mathrm{Cl}^{-}$ electrodes were connected to a voltage clamp that nullified the fluid resistance between the PD-sensing bridges and delivered a short-circuiting current across the tissue. Under these experimental conditions active ion flux across the tissue was represented by the Isc necessary to reduce the transmural PD to zero. Tissue conductance was calculated as the ratio of short-circuit to open-circuit values of PD, or the current necessary to increase the PD to $8.0 \mathrm{mV}$.

EFS. Activation of colonic submucosal nerves was achieved by passing current parallel to the plane of tissues mounted in flux chambers as previously described (11). Stimulus parameters used were $10-\mathrm{Hz}, 15-\mathrm{V}$, and 0.5 -ms duration. The stimulus was applied for $2 \mathrm{~min}$.

Responses to secretory agents. Isc responses to secretagogues were measured by adding drugs directly into the serosal bathing solution. The concentrations chosen were those that are known to evoke maximal Isc responses in adult pigs and other species (12). Changes in lsc during neural stimulation or after addition of secretagogues were recorded on a chart recorder and also input into a computer for later analysis. For experiments involving neural blockade, the neurotoxin TTX $(0.5 \mu \mathrm{M})$ was added to serosal bathing solutions, and the change in Isc that occurred within a $4-\mathrm{min}$ period was recorded. The effect of TTX on Isc was compared with control tissues from the same animals in which Krebs buffer was added in place of the neurotoxin. In other experiments amiloride $(10 \mu \mathrm{M})$ was added to mucosal solutions to inhibit electrogenic $\mathrm{Na}^{+}$absorption, or bumetanide $(10 \mu \mathrm{M})$ was added to serosal solutions to inhibit $\mathrm{Na}^{+}-\mathrm{K}^{+}-2 \mathrm{Cl}^{-}$uptake across the basolateral membranes of colonocytes. These agents were added at least $10 \mathrm{~min}$ before EFS or chemical agonists.

Chemicals. Chemicals and reagents were purchased from Sigma Chemical (St. Louis, MO). All drugs were dissolved in deionized, distilled water except for bumetanide, which was dissolved in dimethyl sulfoxide and Krebs buffer. Stock solutions of $5 \mathrm{HT}$ and norepinephrine contained the monoamine oxidase inhibitor pargyline $(0.1$ $\mathrm{mM}$ ).

Data analysis and statistics. Maximal changes in Isc evoked by either neural or chemical stimulation were calculated by subtracting the basal current before stimulation from the peak current after stimulation and then were normalized to serosal surface area. Minimum sample sizes for all treatments were at least five tissues from at least three piglets per age group. Statistical significance among age groups was determined by either $t$ tests or one-way analysis of variance followed by Duncan's multiple range test for post hoc comparisons. Differences between age groups were considered to be statistically significant if $p \leq 0.05$.

\section{RESULTS}

The mean body weights of piglets used in the experiments were (in $\mathrm{kg}$ ): newborn, $1.2 \pm 0.2 ; 1-\mathrm{d}, 1.2 \pm 0.1$; $5-d, 2.9 \pm 0.3 ; 14-d, 3.2 \pm 0.2$; and weaned, $4.9 \pm 0.2$. Although body weights were not obtained for the fetal pigs in this study, Ferguson et al. (5) reported that the full-term fetal pig weighs approximately $1.2 \mathrm{~kg}$.

Mucosal histology. Because $\mathrm{Cl}^{-}$secretion in colonic tissues is thought to occur from the crypt epithelial cells (13), we determined whether developmental changes in 
the colonic crypt cell population were associated with changes in neurally mediated ion transport. Mean crypt depths in fetal and newborn pigs were not significantly different, but both were lower than in the 1-d-old piglets (Fig. 1). Crypt depths increased significantly from 1-d-old to 5-d-old piglets and then remained constant through the suckling period.

Basal electrical parameters. Mean transmural PD, Isc, and tissue conductance were calculated for each age group $30 \mathrm{~min}$ after the beginning of the experiments. Isc were lowest in fetal piglet colons, were similar from newborn to 14-d-old piglets, and then increased significantly in the newly weaned animals (Fig. $2 A$ ). The pattern for transmural PD was similar to that for Isc except that the difference between fetal tissues and those in older, suckling pigs did not reach statistical significance (Fig. $2 B$ ). Tissue conductance did not vary significantly from fetal through 14-d-old piglets, but it did increase significantly after weaning (Fig. $2 C$ ).

The dependence of basal Isc on electrogenic $\mathrm{Na}^{+} \mathrm{ab}-$ sorption was examined with the $\mathrm{Na}^{+}$channel blocker amiloride. Mucosal addition of amiloride $(10 \mu \mathrm{M}) \mathrm{had}$ little effect in colonic tissues of fetal pigs, but the drug significantly decreased basal Isc as the piglets matured (Fig. 3). In contrast, serosal addition of bumetanide (10 $\mu \mathrm{M})$, an inhibitor of the basolateral $\mathrm{Na}^{+}-\mathrm{K}^{+}-2 \mathrm{Cl}^{-}$ cotransporter, had no significant effect on basal Isc in any age group (data not shown).

Effect of neural blockade on basal Isc. To assess the role of ongoing neural activity in the maintenance of basal ion transport in the piglet colon, we added TTX $(0.5 \mu \mathrm{M})$ or Krebs buffer to serosal bathing solutions when Isc had reached a stable baseline, and the maximum change in Isc within a 4-min period was recorded. TTX significantly reduced basal Isc compared with saline-treated tissues in the fetal, newborn, and 1-d-old piglets (Fig. 4). In older piglets, the reductions in Isc after addition of TTX were not significantly different from those observed over the same time period in control tissues.

Effect of neural stimulation. EFS evoked an increase in Isc that remained elevated above baseline throughout the stimulation period and returned to baseline 5 to $10 \mathrm{~min}$

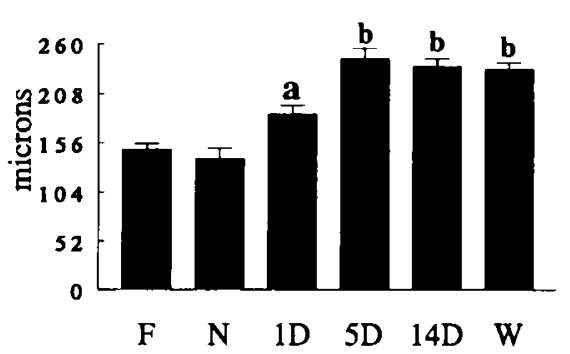

Figure 1. Crypt depths of distal colonic tissues taken from full-term fetal pigs $(F)$, newborns $(N)$, 1-d-old $(I D)$, 5-d-old $(5 D)$, 14-d-old $(14 D)$, and 21-d-old piglets that were weaned for $2 \mathrm{~d}(W)$. "Significantly greater than in $F$ or $N$ groups; "significantly greater than in $F, N$, or $l D$ groups: $p<0.05$ when analyzed by analysis of variance followed by Duncan's multiple range test for post hoc comparisons. Values are means \pm SEM for six to 12 piglets per group.
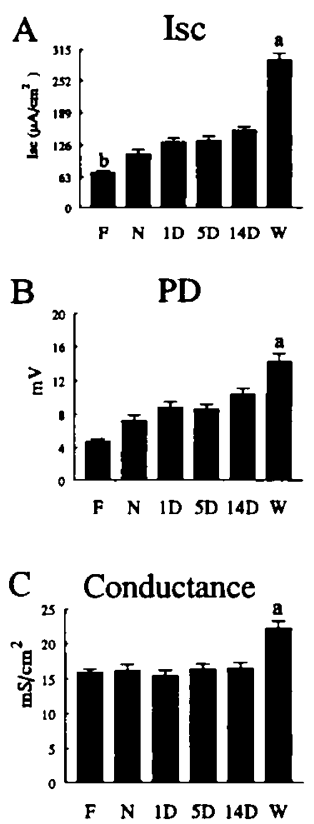

Figure 2. Basal electrical parameters of piglet distal colon. $A$, Isc; $B$, transmural PD; $C$, tissue conductance. "Significantly greater than all other groups, $p<0.05$ when analyzed by analysis of variance followed by Duncan's multiple range test for post hoc comparisons. ${ }^{h}$ Significantly less than all other groups, $p<0.05$. Values are means \pm SEM for 21 to 41 tissues from six to 30 piglets. See Figure 1 for explanation of abbreviations.

after removal of the stimulus. Maximal changes in Isc evoked by neural stimulation did not vary significantly from fetal through 14-d-old piglets; however, neurally evoked responses in weaned piglets were significantly greater than in all other age groups (Fig. 5). Pretreatment of the tissues with TTX produced a significant inhibition of neurally mediated responses in all piglets (Fig. 5). This confirmed the effectiveness of the neurotoxin in blocking neurotransmitter release.

Effect of secretory agonists. The acetylcholine analog carbachol evoked an increase in colonic Isc that was greater in the fetal piglets compared with all other age groups except for the newborn animals (Fig. 6A). Responses in newborns were significantly greater than in the 5-d-old and 14-d-old piglets.

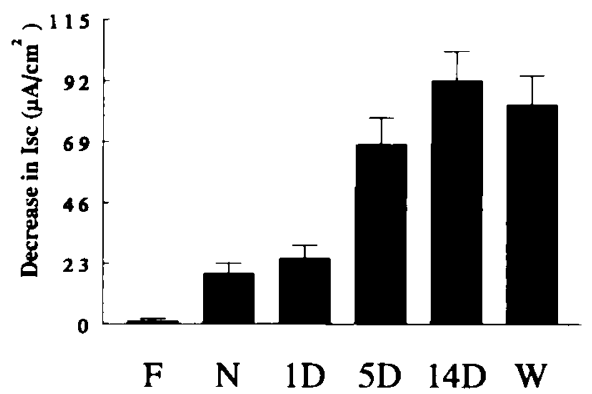

Figure 3. Effect of amiloride on basal Isc. Amiloride $(10 \mu \mathrm{M})$ was added to mucosal bathing solutions, and the maximum change in basal Isc over a 10 -min period was recorded. All decreases in Isc were significantly different from zero ( $p<0.05, t$ test), except for the fetal group. Values are means \pm SEM for 11 to 26 tissues from three to 10 piglets per group. See Figure 1 for explanation of abbreviations. 


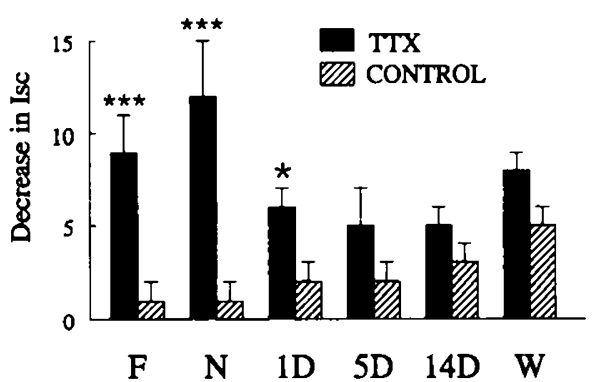

Figure 4. Effect of TTX on basal Isc. Shown are mean ( \pm SEM) decreases in basal Isc evoked by serosal addition of TTX $(0.5 \mu \mathrm{M})$ or Krebs buffer to serosal bathing solutions. Significantly different from control tissues at $p<0.05\left(^{*}\right)$ or $p<0.001\left({ }^{* * *}\right)$ when analyzed by $t$ tests. $n=10$ to 18 tissues from six to 13 piglets for TTX-treated tissues and 12 to 22 tissues from five to 13 piglets for control tissues. See Figure 1 for explanation of abbreviations.

Isc responses to $5-\mathrm{HT}$ were greatest in the fetal pigs compared with all other age groups, but no other significant differences were detected during postnatal development (Fig. 6B).

Norepinephrine evoked large increases in Isc in colonic tissues of all age groups (Fig. $6 \mathrm{C}$ ). Although maximal Isc responses evoked by norepinephrine tended to decline from fetal through 14-d-old piglets and increase again after weaning, no significant differences were observed among any age groups.

Ionic basis of Isc changes. Figure 7 shows Isc responses in tissues pretreated with bumetanide or amiloride, as percentages of control responses in the absence of the drugs. Isc responses to neural stimulation in each tissue were compared with responses in the same tissues before addition of the inhibitors. For carbachol, 5HT, and norepinephrine, mean responses in the presence of bumetanide or amiloride for each age group were compared with mean responses in separate tissues tested in the absence of the inhibitors (Fig. 6).

Isc responses to carbachol, norepinephrine, or $5 \mathrm{HT}$ in the presence of bumetanide were reduced to $58 \%$ or less

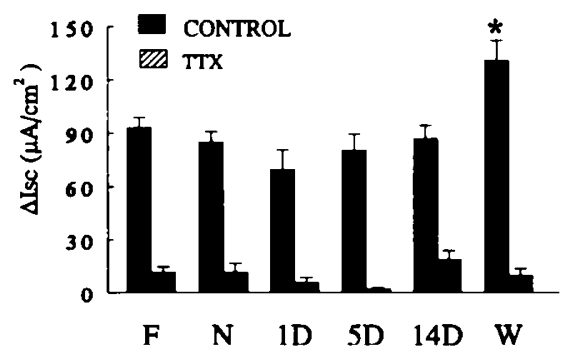

Figure 5. Isc responses to neural stimulation (EFS) in piglet distal colon in the absence (control) and presence of $0.5 \mu \mathrm{M}$ TTX. Neurally evoked changes in Isc were reduced significantly by TTX in all age groups $(p<0.001)$. Isc responses to EFS in control tissues did not vary significantly during development except for responses in weaned piglets, which were significantly greater than in control tissues of all other age groups $\left(^{*}, p<0.05\right.$ when analyzed by analysis of variance followed by Duncan's multiple range test for post hoc comparisons). For control tissues, $n=32$ to 50 tissues from at least five piglets per group; for TTX-treated tissues, $n=5$ to 20 tissues from at least three piglets per group. Values are means \pm SEM. See Figure 1 for explanation of abbreviations.
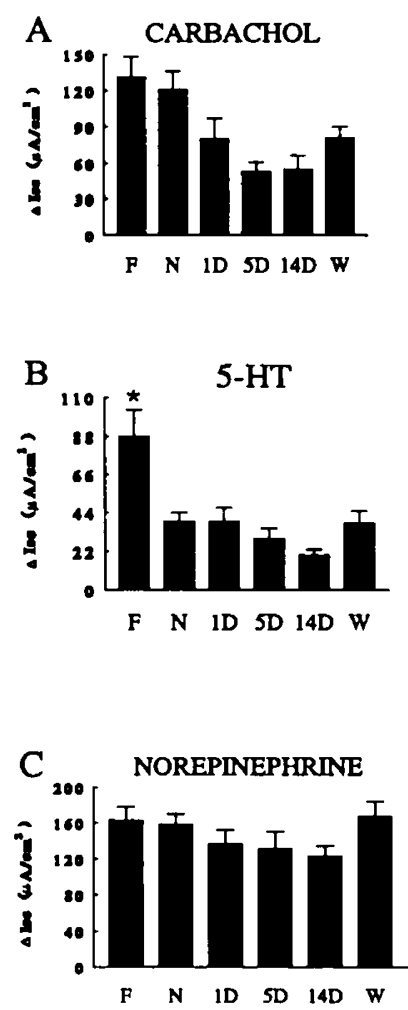

Figure 6. Isc responses to serosal addition of carbachol $(10 \mu \mathrm{M})(A)$, 5HT $(10 \mu \mathrm{M})(B)$, or norepinephrine $(10 \mu \mathrm{M})(C)$ in piglet distal colon. *, Significantly greater than in all other age groups $(p<0.05)$ when analyzed by analysis of variance followed by Duncan's multiple range test for post hoc comparisons. See text for other differences among groups. For carbachol, $n=$ seven to 29 tissues from three to 26 piglets; for $5 \mathrm{HT}, n=$ eight to 21 tissues from three to 12 piglets; for norepinephrine, $n=14$ to 33 tissues from four to 14 piglets.

of control values (Fig. $7 A$ ). In all cases, the reductions were statistically significant $(p<0.05)$. The effect of bumetanide on EFS-induced responses was less pronounced but still significant for each group $(p<0.05)$. In general, pretreatment of tissues with amiloride had no significant effects on subsequent Isc responses to EFS, carbachol, norepinephrine, or 5HT. However, amiloride appeared to enhance the Isc responses to some of the stimuli (Fig. 7B).

To examine further the role of $\mathrm{Cl}^{-}$ions in secretagogue-induced responses, we examined Isc responses in tissues from 1-d-old piglets when $\mathrm{Cl}^{-}$ions were removed from the bathing solutions. Isc responses to all stimuli were significantly reduced in $\mathrm{Cl}^{-}$-free solutions (Fig. 8). Taken together, these results suggest that the effects of these stimuli on colonic ion transport involve increases in $\mathrm{Cl}^{-}$secretion.

\section{DISCUSSION}

The postnatal changes in basal electrical parameters we observed in piglet distal colon are consistent with those reported previously by Cremaschi et al. (8). The gradual increases in basal Isc and PD from the fetal through the weaning stages are thought to be caused by developmental changes in electrogenic $\mathrm{Na}^{+}$absorption 


\section{A BUMETANIDE}
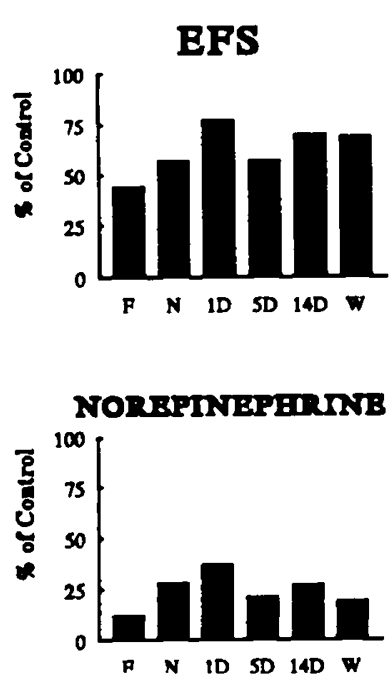
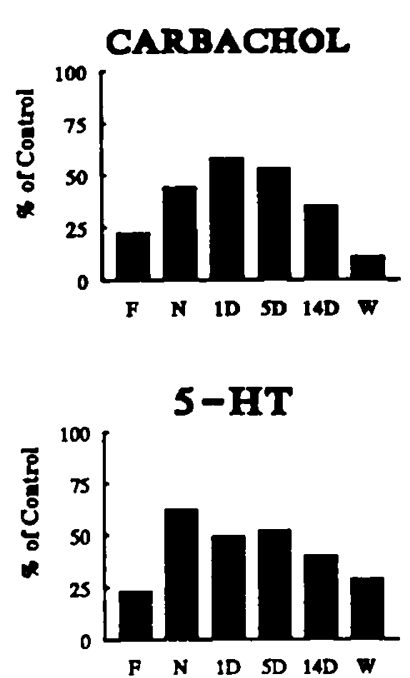

B AMILORIDE
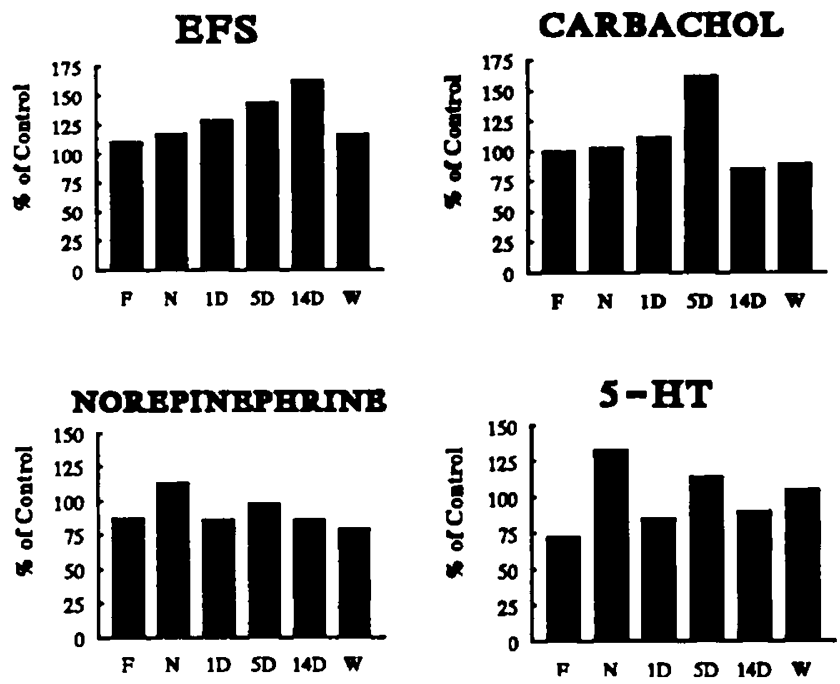

Figure 7. Effect of ion transport inhibitors on Isc responses in piglet distal colon. Values are mean changes in Isc in response to drug addition or EFS, expressed as a percentage of the control response recorded in the absence of the drug. $A$, Effect of bumetanide $(10 \mu \mathrm{M}) . B$, Effect of amiloride $(10 \mu \mathrm{M})$. Control responses are shown in Figures 5 and 6 . Note differences in $y$ axis ranges between $A$ and $B . n=$ five to 19 tissues from at least three piglets per group.

resulting from changes in circulating levels of aldosterone immediately after birth $(5,8)$. This is supported in the present study by the increasing amiloride sensitivity of the basal currents as development progressed. At the concentration used in this study $(10 \mu \mathrm{M})$, amiloride selectively blocks epithelial $\mathrm{Na}^{+}$channels (14). Our laboratory has recently demonstrated the presence of epitopes similar to the renal amiloride-sensitive $\mathrm{Na}^{+}$ channel protein in piglet distal colon (15).

Because basal Isc and PD varied in parallel during most of postnatal development, conductance values, which represent the sum of both active and passive ion flows across the epithelium, were similar from the fetal stage
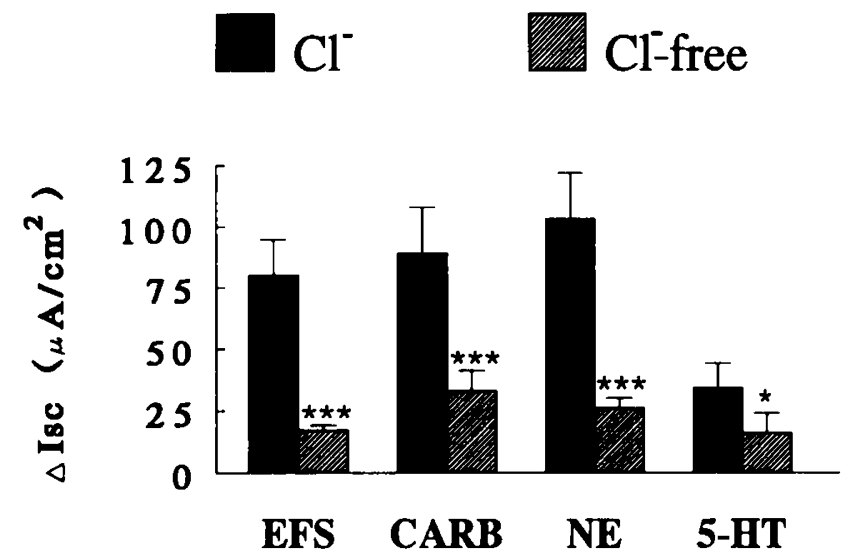

Figure 8. Effect of chloride substitution on Isc changes evoked by secretagogues in 1-d-old piglets. Values are mean ( \pm SEM) Isc changes evoked in the presence or absence of chloride ions. Significantly different from chloride-containing solutions at $p<0.05\left({ }^{*}\right)$ or $p<0.001$ $\left({ }^{* *}\right)$ when analyzed by $t$ tests. Four piglets were used in each of the treatments. $n=$ five to 17 tissues for chloride-containing solutions and six to 13 tissues for chloride-free solutions. CARB, carbachol; $N E$, norepinephrine. through d 14. Thus, although changes in specific transport pathways may occur postnatally, the total ionic permeability of the distal colonic epithelium remains relatively constant. However, we did observe significant increase in basal Isc, PD, and tissue conductance in the newly weaned piglets, which suggests that the weaning process may have altered paracellular or transcellular ion flow across the colonic epithelium. To our knowledge, this effect has not been described previously in piglets, and its ionic basis is as yet unknown. It is also not certain what aspect of the weaning process was responsible for these changes in basal electrical parameters; possibilities include the dietary shift as piglets begin to consume solid food, the stress associated with removal of piglets from the sow, and the self-imposed fast that is common in early weaned piglets (16). Other studies from our laboratory lend support to the latter hypothesis; we have noted a significant increase in jejunal tissue conductance in 21-d-old piglets that were subject to a 48-h fast compared with littermates that continued to feed over this time period (17).

The primary aim of this study was to examine developmental changes in mucosal responses to enteric neurotransmitters. It is now well documented that neuroactive substances are important modulators of ion transport in the adult intestine $(1,2)$; however, apart from the study of Carey and Cooke (3), which used suckling mouse jejunum, very little is known of their effects in the neonatal gut. To our knowledge the present study is the first to address this question in animals as young as the fetal stage. Our results indicate that the ability of the piglet colonic mucosa to respond to both endogenous and exogenous neurotransmitters is well developed at an early age. 
The significant reductions in basal Isc evoked by TTX in the youngest age groups (fetal, newborn, and 1-d-old piglets) suggest that a substantial neural component to basal ion transport exists in the piglet distal colon during the perinatal period and that this component declines in magnitude as piglets mature. Indeed, TTX had no effect on net $\mathrm{Na}^{+}$or $\mathrm{Cl}^{-}$fluxes in distal colonic tissues of 6- to 10 -wk-old weaned pigs (18), although the neurotoxin appears to have variable effects on basal Isc (19). In other intestinal tissues in which a significant effect of TTX on basal Isc has been observed, addition of the neurotoxin increases $\mathrm{Na}^{+}$and $\mathrm{Cl}^{-}$absorption (20-23). This suggests that in the basal state, ongoing activity of submucosal neurons limits the absorptive capacity of the epithelium for these ions $(20,23)$. Thus, the change in sensitivity of the colonic epithelium during postnatal development may reflect an immature system at birth in which secretory influences predominate, followed by the development of an opposing, absorptive tone as the piglets mature. As noted above, the age-related increase in the sensitivity of the colonic epithelium to amiloride is likely due to the increasing influence of circulating aldosterone (8), which may serve to counteract ongoing neurally mediated secretion in the older animals. Other factors that may influence the development of colonic ion transport in piglets include alterations in epithelial sensitivity to basal neurotransmitter release as the piglets mature (such as changes in densities of neural receptors) and developmental changes in the enteric neuronal population that affect the amount or type of neurotransmitters that are released. The enteric nervous system seems to be well developed at birth in guinea pigs, lambs, and human infants (24-26) but continues to mature postnatally in the rat (27). Because similar studies have not been carried out in piglets, the contribution of developmental changes in the enteric nervous system to basal ion transport in this species will require further study.

EFS produced an increase in Isc in all age groups. This nonselective stimulus evokes release of acetylcholine and other noncholinergic neurotransmitters in the mammalian gut $(1,28)$. The neurally evoked changes in ion transport in piglet distal colon were not due to electrical activation of nonneuronal elements in the mucosa, such as epithelial cells, because TTX, which blocks $\mathrm{Na}^{+}$channels on nerves, significantly reduced the Isc response to EFS. Furthermore, Biagi et al. (29) provided evidence that TTX does not directly affect crypt cells in the rabbit colon but does inhibit $\mathrm{Cl}^{-}$secretion in intact colonic sheets through a neurally mediated process. The changes in Isc during neural stimulation of piglet distal colon involved changes in $\mathrm{Cl}^{-}$secretion because the neurally evoked responses were reduced significantly by bumetanide, which inhibits uptake of $\mathrm{Cl}^{-}$across the basolateral membrane. Furthermore, removal of $\mathrm{Cl}^{-}$ions from the solutions bathing the tissues from 1-d-old piglets nearly abolished Isc responses to EFS. EFS has been shown to increase electrogenic $\mathrm{Cl}^{-}$secretion in the distal colon of the guinea pig (30) and in small-intestinal tissues of pigs and other species $(1,22,31)$. However, the inability of bumetanide to abolish neurally evoked Isc responses fully suggests that EFS may alter other ion movements in addition to $\mathrm{Cl}^{-}$, such as $\mathrm{HCO}_{3}{ }^{-}$. Interestingly, the $\mathrm{Na}^{+}$ channel blocker amiloride enhanced the Isc response to neural stimulation in many tissues, particularly in the older animals. As will be discussed below, this observation may help to explain the enhanced secretory responses observed in the fetal and neonatal pigs.

The colonic Isc responses to EFS were similar in all age groups except the newly weaned pigs, which showed enhanced responses compared with the younger piglets. Because of the nonselective nature of the neural stimulus during EFS, it is possible that concomitant release of secretory neurotransmitters with others that simultaneously inhibit secretion or promote absorption (31) may have obscured any developmental changes in neurally evoked secretory responses. We therefore focused our attention on specific neurotransmitters that are known to evoke changes in $\mathrm{Cl}^{-}$secretion in swine and in other mammalian species. The fact that Isc responses to exogenous addition of carbachol, 5HT, and norepinephrine were all significantly reduced in $\mathrm{Cl}^{-}$-free solutions in 1-d-old piglets and were also reduced by bumetanide in all age groups suggested that the agonists exerted their effects through increases in $\mathrm{Cl}^{-}$secretion. Traynor et al. (12) also reported that both carbachol and norepinephrine evoke increases in $\mathrm{Cl}^{-}$secretion in distal colons of 6- to 10-wk-old, weaned pigs. Although its actions in the pig colon have not been studied, 5HT is known to stimulate $\mathrm{Cl}^{-}$secretion in guinea pig distal colon (32). The stimulatory effect of norepinephrine on $\mathrm{Cl}^{-}$secretion in swine distal colon is markedly different from that reported in small- and large-intestinal tissues of other species, where norepinephrine reduces Isc by stimulating $\mathrm{Na}^{+}$and $\mathrm{Cl}^{-}$ absorption and inhibiting $\mathrm{Cl}^{-}$and $\mathrm{HCO}_{3}^{-}$secretion (2, $33,34)$.

As we observed for Isc responses to EFS, the secretory responses to carbachol, 5HT, and norepinephrine in fetal and newborn colons were as great, or greater, than those in the older animals. This response occurred despite a reduced crypt population in the younger piglets. We examined in more detail the relationship between crypt depth, piglet age, and Isc responses to one of the secretagogues, carbachol, using a two-way analysis of variance. Both crypt depth and piglet age were found to exert significant, negative influences on the secretory response evoked by carbachol $(p<0.05$ for both independent variables). Thus, because the crypt is thought to be the site of $\mathrm{Cl}^{-}$and fluid secretion in colonic tissues (13), a greater number of secretory cells cannot account for the age-related variations in responses to these secretory agonists (35). Rather, our results suggest that the sensitivity of the piglet colonocytes to secretory agonists may be particularly high shortly before and immediately after birth. Interestingly, Yagi et al. (36) reported that 5HT was 12 times more potent in stimulating contraction of colonic smooth muscle in newborn versus weanling 
rabbits. Heitkemper and Bond (37) also found that tension produced by thyrotropin-releasing hormone in longitudinal muscle strips of rat distal colon was significantly greater in 3- and 7-d-old rats compared with 21-d-old animals. Thus, enhanced sensitivity to agonist action in neonates may include effects on intestinal smooth muscle and epithelial cells involved in ion transport.

The mechanism responsible for the heightened sensitivity of fetal and neonatal piglet colons to secretory agonists is unknown. However, our results and a review of the literature reveal several possibilities. The tendency for amiloride to enhance ion transport responses in some of the tissues (Fig. $7 B$ ) suggests one mechanism whereby developmental changes in electrogenic $\mathrm{Na}^{+}$absorption are linked to driving forces responsible for $\mathrm{Cl}^{-}$secretion. Because amiloride at concentrations of $10 \mu \mathrm{M}$ or less inhibits electrogenic $\mathrm{Na}^{+}$entry into colonocytes (14), the resulting hyperpolarization of the cells would, in effect, increase the electrical driving force for $\mathrm{Cl}^{-}$exit through apical membrane channels $(38,39)$. Thus, amiloridetreated tissues may be "primed" to secrete on stimulation by agonists that increase $\mathrm{Cl}^{-}$secretion. This could explain why the drug appeared to enhance Isc responses in some of the age groups. Because electrogenic $\mathrm{Na}^{+}$ absorption is already reduced in fetal and neonatal pigs $(5,8)$, colonocytes of these piglets may also be "primed" to secrete relative to responses in older piglets in which the opposing effect of ongoing $\mathrm{Na}^{+}$absorption is well developed.

Changes in epithelial sensitivity to secretory agonists during postnatal development could also be caused by changes in apical membrane proteins that are involved in ion transport or to changes in intracellular pathways that link basolateral receptor activation with transporterchannel function. For example, small-intestinal tissues of young children and animals (including piglets) are more responsive than those of adults to certain nonneuronal secretagogues such as the heat-stable enterotoxin of Escherichia coli $\left(\mathrm{ST}_{\mathrm{a}}\right)(40,41)$. This effect appears to be the result of age-related differences in $\mathrm{ST}_{\mathrm{a}}$ binding, guanylate cyclase activation, and $\mathrm{ST}_{\mathrm{a}}$ receptor size $(40,41)$. It is also possible that changes in colonocyte membrane lipid composition during postnatal development alter the activity of apical ion transport proteins through effects on the surrounding lipid microenvironment $(42,43)$. Further studies are needed to determine whether any of these factors play a role in the developmental changes in secretory activity of the piglet distal colon.

We noted a consistent trend for enhanced secretory responses immediately after weaning in 21-d-old piglets compared with 14-d-old piglets that were still suckling. Although this pattern could be the result simply of increasing age, other evidence from our laboratory suggests that the sensitivity of the gut to secretory agonists is altered by the weaning process, possibly resulting from the short-term fast that is typical of the first few days after weaning in piglets (16). Indeed, the sensitivity of the small intestine to secretory agonists is significantly enhanced by a 48-h fast in early weaned piglets (17).

In summary, we have shown that neurally mediated pathways that regulate ion transport appear to be well developed in the piglet distal colon at an early age. These results thus provide a basis with which to extend existing knowledge of the neural regulation of intestinal ion transport to the neonate. Our studies revealed several instances where neurally mediated ion transport, including basal ion transport and stimulated secretion, was greater in the fetal and newborn colon compared with older animals. These findings suggest that the sensitivity of distal colonic tissues to agents that act through nerves or activate neurotransmitter receptors on epithelial cells should be considered in the cause and management of diarrheal diseases that affect preterm infants and newborns. Finally, our results indicate that a change in the sensitivity to secretory agonists may also take place immediately after weaning in piglets, which may help to explain the propensity for diarrheal disease that is often observed at this time (44).

Acknowledgments. The authors thank Nancy Sills and Dane Jespersen for excellent technical assistance.

\section{REFERENCES}

1. Cooke HJ 1987 Neural and humoral regulation of small intestinal electrolyte transport. In: Johnson LR (ed) Physiology of the Gastrointestinal Tract. 2nd Ed. Raven Press, New York, pp 1307-1350

2. Brown DR, Miller RJ 1991 Neurohumoral control of fluid and electrolyte transport in intestinal mucosa. In: Schultz SG (ed) Handbook of PhysiologyThe Gastrointestinal System IV. American Physiological Society, Bethesda. MD, pp 527-589

3. Carey HV, Cooke HJ 1989 Neuromodulation of intestinal transport in the suckling mouse. Am J Physiol 256:R481-R486

4. Hills F, James PS, Paterson JYF, Smith MW 1980 Delayed development of amiloride-sensitive sodium transport in lamb distal colon. J Physiol (Lond) 303:371-384

5. Ferguson DR, James PS, Paterson JYF, Saunders JC, Smith MW 1979 Aldosterone induced changes in colonic sodium transport occurring naturally during development in the neonatal pig. J Physiol (Lond) 292:495-504

6. O'Loughlin EV, Hunt DM, Kreutzmann D 1990 Postnatal development of colonic electrolyte transport in rabbits. Am J Physiol 258:G447-G453

7. Finkel Y, Aperia A. Eklof AC 1985 Development of colonic fluid and electrolyte transport: influence of weaning pattern. J Pediatr Gastroenterol Nutr $4: 457-462$

8. Cremaschi D, Ferguson DR, Henin S, James PS, Meyer G, Smith MW 1979 Postnatal development of amiloride sensitive sodium transport in pig distal colon. J Physiol (Lond) 292:481-494

9. Pacha J, Popp M, Capek K 1987 Amiloride-sensitive sodium transport of the rat distal colon during early postnatal development. Eur J Physiol 409:194-199

10. Jenkins HR, Fenton TR, McIntosh N, Dillon MJ, Milla PJ 1990 Development of colonic sodium transport in early childhood and its regulation by aldoste rone. Gut 31:194-197

11. Carey HV, Cooke HJ, Zafirova M 1985 Mucosal responses evoked by stimulation of ganglion cell somas in the submucosal plexus of the guinea pig ileum. J Physiol (Lond) 364:69-79

12. Traynor TR, Brown DR, O'Grady SM 1991 Regulation of ion transport in porcine distal colon: effects of putative neurotransmitters. Gastroenterology 100:703-710

13. Welsh MJ, Smith PL, Fromm M, Frizzell RA 1982 Crypts are the site of intestinal fluid and electrolyte secretion. Science 218:1219-1221

14. Smith PR, Benos DJ 1991 Epithelial $\mathrm{Na}^{+}$channels. Ann Rev Physiol 53:509. 530

15. Carey HV, Hayden UL, Spicer SS, Schulte BA, Benos DJ 1994 Localization of amiloride-sensitive $\mathrm{Na}$ channels in intestinal epithelia. Am J Physio 266:G504-G510)

16. Bark LJ, Crenshaw TD, Leibbrandt VD 1986 The effect of meal intervals and weaning on feed intake of early weaned pigs. J Anim Sci 62:1233-1239

17. Carey HV, Hayden UL, Tucker KE 1994 Fasting alters basal and stimulated ion transport in piglet jejunum. Am J Physiol 267:R156-R163

18. Hammerbeck DM, Brown DR 1993 Neurally mediated actions of leukotrienes on ion transport in guinea pig distal colon. J Pharmacol Exp Ther 264:384-390 
19. Traynor TR, Brown DR, O'Grady SM 1993 Effects of inflammatory mediators on electrolyte transport across the porcine distal colon epithelium. J Pharmacol Exp Ther 264:61-66

20. Carey HV, Cooke HJ 1989 Tonic activity of submucosal neurons influences basal ion transport. Life Sci 44:1083-1088

21. Sheldon RJ, Malarchik ME, Fox DA. Burks TF. Porreca F 1989 Pharmacological characterization of neural mechanisms regulating mucosal ion transport in mouse jejunum. J Pharmacol Exp Ther 249:572-582

22. Hildebrand KR. Brown DR 1990 Intrinsic neuroregulation of ion transport in porcine distal jejunum. J Pharmacol Exp Ther 255:285-292

23. Andres H, Bock R, Bridges RJ, Rummel W, Schriner J 1985 Submucosal plexus and electrolyte transport across rat colonic mucosa. J Physiol (Lond) 364:301-312

24. Saffrey MJ, Burnstock G 1988 Distribution of peptide-immunoreactive nerves in the foetal and newborn guinea-pig caecum. Cell Tissue Res 253:105-114

25. Houghton PE, Buchan AMJ, Challis JRG 1992 Ontogeny of the distribution and colocalization of calbindin D28K within neural and endocrine cells of the gastrointestinal tract of fetal and neonatal sheep. Regul Pept 37:73-83

26. Buchan AMJ, Bryant MG, Polak JM, Gregor M, Ghatei MA, Bloom SR 1981 Development of regulatory peptides in the human fetal intestine. In: Bloom SR, Polak JM (eds) Gut Hormones. Churchill Livingstone, Edinburgh, UK, pp $119-124$

27. Gabella G 1971 Neuron size and number in the myenteric plexus of the newborn and adult rat. J Anat 109:81-95

28. Javed NH, Cooke HJ 1992 Acetylcholine release from colonic submucosal neurons associated with chloride secretion in the guinea pig. Am J Physiol 262:G131-G136

29. Biagi B, Wang Y-Z, Cooke HJ 199) Effects of tetrodotoxin on chloride secretion in rabbit distal colon: tissue and cellular studies. Am J Physio 258:G223-G230

30. Kuwahara A, Bowen S, Wang J, Condon C, Cooke HJ 1987 Epithelia responses evoked by stimulation of submucosal neurons in guinea pig distal colon. Am J Physiol 252:G667-G674

31. Carey HV, Zafirova M 1990 Adrenergic inhibition of neurally evoked secretion in ground squirrel intestine. Eur J Pharmacol 181:43-50
32. Cooke HJ, Wang Y-Z, Frieling T, Wood JD 1991 Neural 5-hydroxytryptamine receptors regulate chloride secretion in guinea pig distal colon. Am J Physiol 261:G833-G840

33. Chang EB, Field M. Miller RJ 1983 Enterocyte alpha - -adrenergic receptors: yohimbine and p-aminoclonidine binding relative to ion transport. Am J Physiol 244:G76-G82

34. Field M. McColl I 1973 lon transport in rabbit ileal mucosa lll. Effects of catecholamines. Am J Physiol 225:852-857

35. Braaten B, Madara JL, Donowitz M 1988 Age-related loss of nongoblet crypt cells parallels decreased secretion in rabbit descending colon. Am J Physiol 255:G72-G84

36. Yagi H, Snape Jr WJ, Hyman PE 1991 Developmental changes in agonistmediated colonic smooth muscle contraction in the rabbit. Pediatr Res 29:20-23

37. Heitkemper MM, Bond EF 1990 Age-related variations in jejunum and distal colon contractile response to thyrotropin-releasing hormone in vitro. Biol Neonate $58: 8-15$

38. Welsh MJ 1987 Electrolyte transport by airway epithelia. Physiol Rev 67:1143-1184

39. Traynor TR, O'Grady SM 1992 Mechanisms of $\mathrm{Na}$ and $\mathrm{Cl}$ absorption across the distal colon epithelium of the pig. J Comp Physiol 162:47-53

40. Guarino A, Cohen MB, Giannella RA 1987 Small and large intestinal guanyl. ate cyclase activity in children: effect of age and stimulation by Escherichia coli heat-stable enterotoxin. Pediatr Res 21:551-555

41. Mezoff AG, Jensen NJ, Cohen MB 1991 Mechanisms of increased susceptibitity of immature and weaned pigs to Escherichia coli heat-stable enterotoxin. Pediatr Res 29:424-428

42. Schwarz SM. Hostetler B, Ling S, Mone M, Watkins JB 1985 Intestinal membrane lipid composition and fluidity during development in the rat. Am J Physiol 248:G20)-G207

43. Alessandri J, Guesnet P, Arfi TS, Durand G 1991 Changes in fatty acid composition during cell differentiation in the small intestine of suckling piglets. Biochim Biophys Acta Lipids Lipid Metab 1086:34()-348

44. Hampson DJ, Smith WC 1986 Influence of creep feeding and dietary intake after weaning on malabsorption and occurrence of diarrhoea in the newly weaned pig. Res Vet Sci 41:63-69 